\title{
Evaluation and treatment of hypertensive crises in children
}

\author{
This article was published in the following Dove Press journal: \\ Integrated Blood Pressure Control \\ 16 March 2016 \\ Number of times this article has been viewed
}

\author{
Deborah R Stein \\ Michael A Ferguson \\ Division of Nephrology, Boston \\ Children's Hospital, Harvard Medical \\ School, Boston, MA, USA
}

\begin{abstract}
Hypertensive crises in children are medical emergencies that must be identified, evaluated, and treated promptly and appropriately to prevent end-organ injury and even death. Treatment in the acute setting typically includes continuous intravenous antihypertensive medications with monitoring in the intensive care unit setting. Medications commonly used to treat severe hypertension have been poorly studied in children. Dosing guidelines are available, although few pediatric-specific trials have been conducted to facilitate evidence-based therapy. Regardless of what medication is used, blood pressure should be lowered gradually to allow for accommodation of autoregulatory mechanisms and to prevent cerebral ischemia. Determining the underlying cause of the blood pressure elevation may be helpful in guiding therapy.

Keywords: hypertensive crisis, hypertensive urgency, hypertensive emergency, antihypertensive medications
\end{abstract}

\section{Introduction}

Hypertension in children and adolescents is defined as systolic and/or diastolic blood pressure (BP) equal to or exceeding the 95th percentile for age, sex, and height on repeated measurements. ${ }^{1}$ In those with confirmed hypertension, BP is further staged based on severity. Stage 1 hypertension is systolic and/or diastolic BP between the 95th percentile and the 99 th percentile $+5 \mathrm{mmHg}$ for age, sex, and height; stage 2 hypertension refers to levels exceeding the 99 th percentile $+5 \mathrm{mmHg}$. Table 1 describes the full classification schema for childhood BP as detailed in the Fourth Report of the National High Blood Pressure Education Program (NHBPEP). ${ }^{1}$

Hypertensive crisis is broadly defined as a severe elevation in BP that is life threatening and has the potential to cause rapid end-organ damage. Hypertensive crises can be further categorized as hypertensive urgencies and hypertensive emergencies. Hypertensive urgency is generally understood to be a severe, often acute, elevation in BP without demonstrable end-organ damage, while hypertensive emergency is a similar elevation in BP with concomitant end-organ damage. In adults, BP exceeding 180/120 $\mathrm{mmHg}$ fulfills criteria for hypertensive crisis; ${ }^{2}$ however, there is no analogous discrete BP cutoff for children and adolescents. This is not unexpected given the variability of normative absolute BP values in the pediatric population based on age, sex, and height.

It is, however, somewhat surprising that there is not greater consensus about what $\mathrm{BP}$ percentiles would raise concern for impending hypertensive crisis in children and adolescents. The NHBPEP Fourth Task Force Report does not comment in detail about a specific threshold for risk of hypertensive crisis, although it does provide a vague
Correspondence: Michael A Ferguson Division of Nephrology, Boston Children's Hospital, Harvard Medical School, 300 Longwood Avenue, Boston, MA 02115 , USA

Tel + I 6173556129

$\mathrm{Fax}+\mathrm{I} 6177300569$

Email michael.ferguson@childrens. harvard.edu
Integrated Blood Pressure Control 2016:9 49-58

(c) (1) (-) ( 2016 Stein and Ferguson. This work is published and licensed by Dove Medical Press Limited. The full terms of this license are available at https://www.dovepress.com/ cc) work you hereby accept the Terms. Non-commercial uses of the work are permitted without any further permission from Dove Medical Press Limited, provided the work is properly attributed. For permission for commercial use of this work, please see paragraphs 4.2 and 5 of our Terms (https://www.dovepress.com/terms.php).
Dovepress

http://dx.doi.org/10.2147/IBPC.S50640

\section{9}


Table I Classification of BP in children

\begin{tabular}{ll}
\hline BP classification & BP percentiles \\
\hline Normal & SBP and DBP $<90$ th percentile \\
Prehypertension & SBP or DBP 90 th to $<95$ th percentile; or \\
& BP $>120 / 80 \mathrm{mmHg}$ even if $<90$ th percentile \\
Stage I hypertension & SBP or DBP $\geq 95$ th-99th percentile $+5 \mathrm{mmHg}$ \\
Stage 2 hypertension & SBP or DBP $>99$ th percentile $+5 \mathrm{mmHg}$ \\
\hline
\end{tabular}

Abbreviations: BP, blood pressure; DBP, diastolic blood pressure; SBP, systolic blood pressure.

statement regarding "blood pressures well above the 99th percentile". ${ }^{1}$ Other authors advocate for a more defined threshold, typically those BP values that exceed the limit for stage 2 hypertension (Table 1).,

Regardless of the threshold used, accurate measurement of BP is important in identifying all children with hypertension and is critical for those with severe hypertension with the potential for end-organ damage. While the gold standard for BP measurement is intra-arterial monitoring, this is not feasible in the outpatient and emergency department setting. Oscillometric monitoring is the most common screening method, although elevated readings obtained using this modality require confirmation by manual auscultation. The BP cuff should have 1) an inflatable bladder width that is a minimum of $40 \%$ of the arm circumference at the midpoint of the upper arm and 2) a length that is $80 \%-100 \%$ of the arm circumference. Incorrect cuff size can lead to erroneous $\mathrm{BP}$ readings, particularly when the cuff used is inappropriately small.

A high level of awareness on the part of the practitioner is also required. Studies have consistently shown that elevated $\mathrm{BP}$ is underrecognized in the pediatric population. ${ }^{5-7}$ Appropriate interpretation of BP values is obviously paramount, particularly in young children in whom signification elevations in BP are less obvious. BP measurements that meet criteria for stage 2 hypertension require prompt investigation, although there is considerable practice variability regarding criteria for admission to the hospital, pace of evaluation, and manner in which antihypertensive medications are introduced.

\section{Etiology}

Historically, hypertension in childhood and adolescence was thought to result largely from some other underlying disease process, typically involving the renal, cardiovascular, or endocrine system (Table 2). More recently, primary hypertension has become much more prevalent in the pediatric population, particularly in older children. The ongoing obesity epidemic is almost certainly responsible for this evolving trend. ${ }^{89}$
Table 2 Causes of hypertensive crisis in childhood and adolescence

Renal

Cystic dysplasia

Autosomal recessive polycystic kidney disease

Autosomal dominant polycystic kidney disease

Reflux nephropathy

Renal scarring

Glomerulonephritis

Renal vein thrombosis

Renal artery stenosis

Hemolytic uremic syndrome

Cardiovascular

Coarctation of the aorta

Midaortic syndrome

Arteritis

Endocrine

Cushing syndrome

Hyperthyroidism

Rare forms of congenital adrenal hyperplasia

Malignancy

Neuroblastoma

Pheochromocytoma

Wilms' tumor

Medications/toxins

Amphetamines

Anabolic steroids

Caffeine (newborns)

Calcineurin inhibitors

Cocaine

Corticosteroids

Erythropoietin

Phenylephrine eye drops (newborns)

Phenylpropanolamines

Pseudoephedrine

Theophylline (newborns)

Neurologic

Central nervous system tumors

Increased intracranial pressure

Seizure

Intracranial hemorrhage

Autonomic dysfunction

Other

Primary hypertension

Pregnancy

Gordon syndrome

Liddle syndrome

Apparent mineralocorticoid excess

Glucocorticoid-remediable aldosteronism

Medication noncompliance in known hypertensive patient

In the case of hypertensive crises, most authors agree that secondary causes are most frequently to blame. ${ }^{3,10,11}$ There are older case series that support this assertion. In a series of 110 patients admitted with severely elevated BP from 1975 to 1985 , Deal et $\mathrm{al}^{12}$ reported that at least $89 \%$ had a secondary etiology identified, with renal causes being by 
far the most common. ${ }^{12}$ There is emerging evidence, albeit limited, that primary hypertension may be playing a larger role than previously thought. In a retrospective analysis of 55 children presenting to an emergency department with hypertensive crisis, Yang et $\mathrm{al}^{4}$ reported that approximately half the number were ultimately thought to have primary hypertension. That being said, $>70 \%$ of younger children $(<12$ years of age) with elevated BP were found to have an underlying cause, with renal disease being the most prevalent. ${ }^{4}$ It should be noted that a majority of patients included in this review (46/55) presented with hypertensive urgency rather than hypertensive emergency. The authors did not provide details regarding secondary vs primary causes for those two subgroups, although two of the five who presented with hypertensive encephalopathy were not found to have an underlying etiology for their hypertension.

\section{Clinical presentation}

Children with severe hypertension may present in a number of forms, ranging from entirely asymptomatic to severely disabled. Some of the variations in terms of presentation may be related to age (Table 3). For example, infants and young children tend to present with nonspecific findings such as irritability, poor feeding, or failure to thrive. There is also some evidence that younger children ( $\leq 6$ years) are more likely than older children to present with change of consciousness or seizure activity. ${ }^{13}$ Older children who are able to communicate their symptoms may report headache, acute visual changes, dizziness, chest discomfort, or nausea and vomiting. Although uncommon, orthopnea, shortness of breath, and edema may suggest concomitant heart or renal failure.

Table 3 Presenting features in children with hypertensive crisis

Infants and young children ( $\leq 6$ years)
Irritability
Feeding disturbance
Vomiting
Failure to thrive
Seizure activity
Altered mental status
Congestive heart failure
Older children ( $>6$ years) and adolescents
Headache
Dizziness
Acute visual disturbance
Facial nerve palsy
Chest tightness
Tachycardia/palpitations
Nausea/vomiting
Asymptomatic

Complications associated with hypertensive crises are typically related to the cardiac, renal, and central nervous systems. According to definition, all children with hypertensive emergency exhibit overt evidence of end-organ damage. In the setting of hypertensive urgency, subclinical end-organ damage, such as left ventricular hypertrophy, hypertensive retinopathy, or microalbuminuria, may be present.

\section{Evaluation}

Clinical assessment of any child with hypertensive crisis must include a detailed history and physical examination. Risk factors for hypertension should be assessed and noted, as these may lead to clues regarding the etiology of the hypertension and thus affect therapeutic choices. History should include recent events, such as medication changes or exposures to toxins including ingestion of medications or nonmedical compounds, as well as more remote elements, such as perinatal events including premature birth or umbilical artery catheterization. A history of urinary tract infections or frequent febrile illnesses as a young child raises the possibility of renal scarring or reflux nephropathy. In adolescent girls, possible pregnancy must be considered. Episodes of flushing, pallor, diaphoresis, and palpitations may suggest an underlying endocrine or metabolic disorder.

A thorough physical examination with careful attention not only to possible clues as to the underlying etiology of the BP elevation but also to findings that may be indicative of end-organ damage and/or comorbid conditions is mandated (Table 4). Similar goals hold true for laboratory testing and diagnostic imaging. The typical approach to the child with confirmed hypertension tends to be measured: initially, screening studies are performed (complete blood count, electrolytes, blood urea nitrogen, serum creatinine, urinalysis, and renal ultrasonography), with subsequent completion of additional studies as indicated based on the clinical situation. However, the higher degree of acuity in those who present with hypertensive crisis typically demands a more expansive approach to initial testing in an effort to elucidate the cause of hypertension as well as identify end-organ damage in an expeditious manner (Table 5). Although results from such studies are expected to help inform eventual therapeutic options to control BP over the long term, initiation of antihypertensive medications should never be delayed in deference to testing in the setting of hypertensive crisis.

\section{Treatment in the emergency setting} The NHBPEP Fourth Report on the Diagnosis, Evaluation, and Treatment of High Blood Pressure in Children and 
Table 4 Findings of interest on physical examination of children with hypertensive crisis

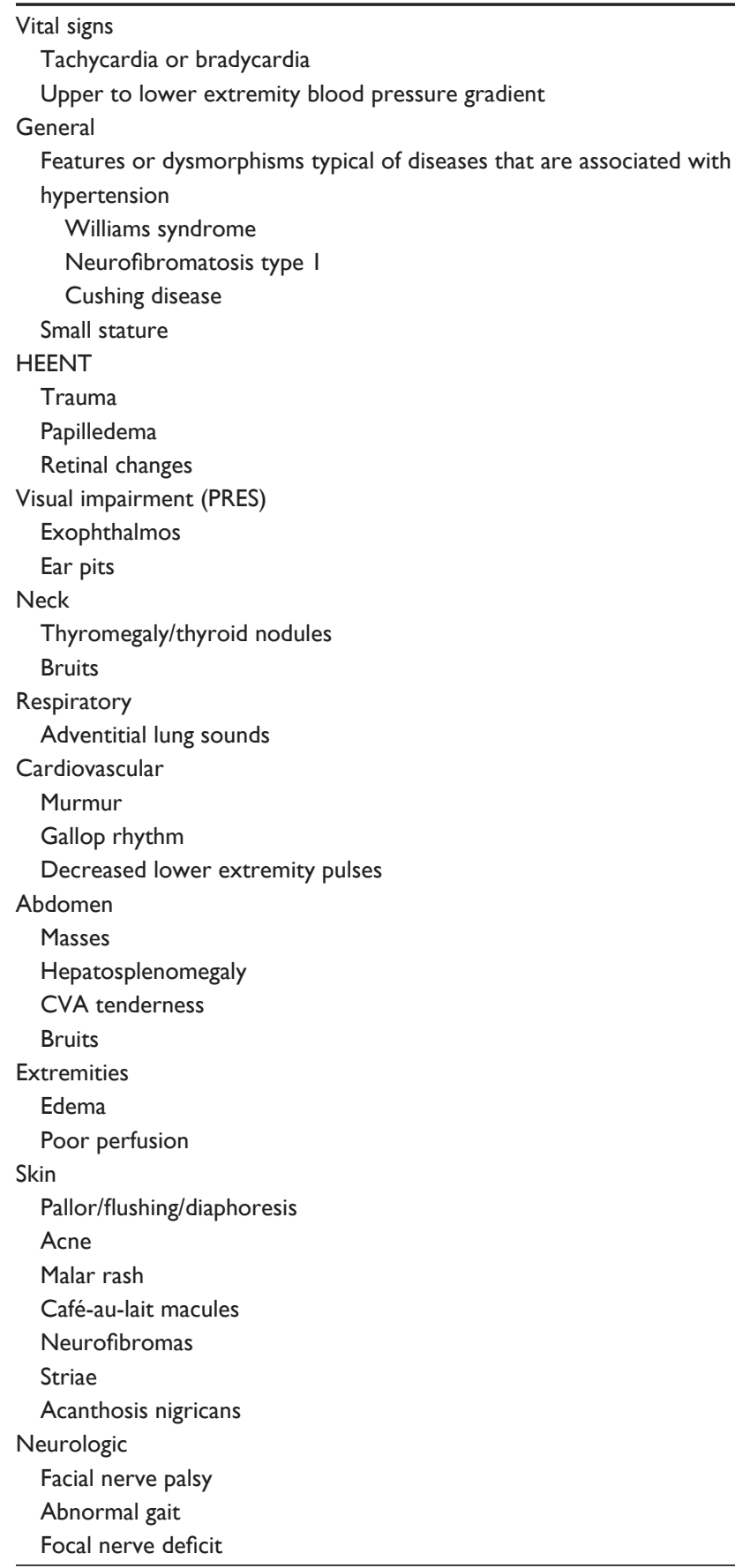

Abbreviations: CVA, costovertebral angle; HEENT, head, eyes, ears, nose, and throat; PRES, posterior reversible encephalopathy syndrome.

Adolescents outlines recommendations to lower the BP to 1) less than the 95 th percentile in children with hypertension and no end-organ damage and 2) less than the 90th percentile in children with end-organ damage, secondary hypertension, and/or comorbid conditions such as underlying renal disease, heart disease, or diabetes. ${ }^{1}$ In those with hypertensive crisis, the BP should be lowered in a gradual manner in an effort to reach the goal pressure over a period of days rather than hours.
Table 5 Evaluation of a child with hypertensive crisis

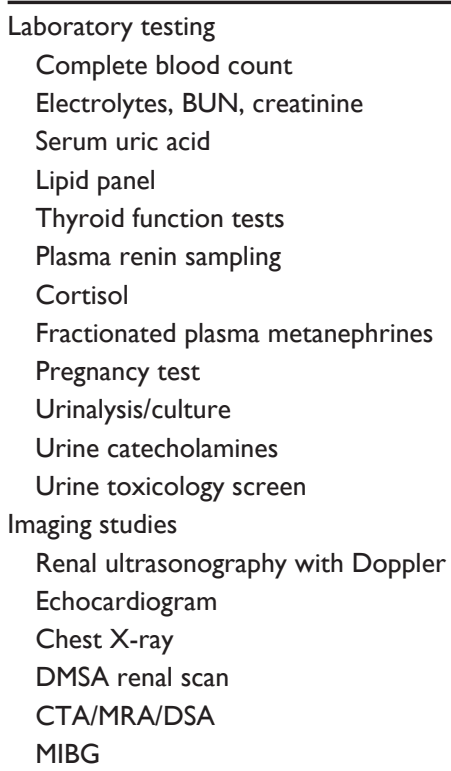

Abbreviations: BUN, blood urea nitrogen; CTA, computed tomography angiogram; DMSA, dimercaptosuccinic acid; DSA, digital subtraction angiography; MIBG, metaiodobenzylguanidine; MRA, magnetic resonance angiogram.

In patients with chronic hypertension, cerebral autoregulatory mechanisms adapt to protect the brain from ischemia. In this setting, children cannot adapt to a rapid decline in $\mathrm{BP}$, and hence a rapid lowering of BP can lead to cerebral ischemia and transient or permanent neurologic dysfunction due to decreased cerebral perfusion. Similar effects may be seen in the kidney as well. In a retrospective review of children who presented with hypertensive emergency between 1975 and 1985, Deal et $\mathrm{al}^{12}$ reported that complications of therapy were much more likely during an era when the goal was rapid reduction in $\mathrm{BP}(23 \%)$ vs one when the goal was more gradual correction (4\%). Complications cited included transient visual loss, transient acute renal failure, permanent visual loss, and transverse ischemic myelopathy. ${ }^{12}$

A reasonable approach to $\mathrm{BP}$ reduction in children with severely elevated BP has been described by Flynn and Tullus, ${ }^{3}$ who recommend that the BP be reduced by $25 \%$ of the planned reduction over the first 8-12 hours, a further $25 \%$ over the next 8-12 hours, and the final $50 \%$ over the following 24 hours. Our own experience is that it is often difficult to reach the goal BP reduction in the first 48 hours of treatment, particularly in those with secondary hypertension, and that augmented therapy may be required over additional days to achieve adequate BP control.

All patients with hypertensive crisis require intravenous (IV) access for administration of antihypertensive medication and provision of fluids and other medications as needed. For initial treatment of hypertensive crisis, IV agents are preferred as these are reliably administered, have rapid onset 
of action, and can be titrated rapidly to achieve the desired effect. In some settings, particularly when IV access is difficult or with less severe elevations in BP, oral medications may be used.

Antihypertensive medications used in children with hypertensive crisis are listed in Table 6 . It should be noted that few of these medications have been studied adequately in the pediatric population and thus safety and efficacy data to guide dosing are limited. Of those medications listed, only hydralazine (oral and IV), fenoldopam, sodium nitroprusside, and minoxidil have pediatric labeling approved by the United States Food and Drug Administration (FDA).

\section{Medications}

As previously mentioned, the preferred approach to the initial management of hypertensive crises is the use of IV medications;

Table 6 Antihypertensive medications for management of hypertensive crisis in children

\begin{tabular}{|c|c|c|c|}
\hline Medication & Class & Dose & Comments \\
\hline \multicolumn{4}{|l|}{ Oral } \\
\hline \multirow[t]{3}{*}{ Clonidine } & Central & $0.05-0.1 \mathrm{mg}$ per dose & Onset of action: $30-60$ minutes \\
\hline & $\alpha$-agonist & to maximum dose of $0.8 \mathrm{mg}$ & Adverse effects: sedation, bradycardia \\
\hline & & total dose & Other: risk of rebound hypertension if standing doses are withdrawn abruptly \\
\hline \multirow[t]{3}{*}{ Isradipine } & $\mathrm{CCB}$ & $0.05-0.1 \mathrm{mg} / \mathrm{kg}$ per dose, & Onset of action: I hour \\
\hline & & up to $5 \mathrm{mg}$ per dose & Adverse effects: headache, nausea, flushing, hypotension \\
\hline & & & Other: available as extemporaneously prepared suspension \\
\hline \multirow[t]{3}{*}{ Minoxidil } & Vasodilator & $0.1-0.2 \mathrm{mg} / \mathrm{kg}$ per dose & Onset of action: 30 minutes \\
\hline & & & $\begin{array}{l}\text { Adverse effects: EKG (T-wave) changes, edema, and hypertrichosis with } \\
\text { chronic use }\end{array}$ \\
\hline & & & Other: long duration of action \\
\hline \multirow[t]{3}{*}{ Nifedipine } & $\mathrm{CCB}$ & $\begin{array}{l}0.1-0.25 \mathrm{mg} / \mathrm{kg} \text { per dose up } \\
\text { to } 10 \mathrm{mg} \text { per dose }\end{array}$ & $\begin{array}{l}\text { Onset of action: I-5 minutes (bite and swallow); within 20-30 minutes, } \\
\text { if capsule taken whole }\end{array}$ \\
\hline & & & Adverse effects: hypotension, flushing, tachycardia, syncope \\
\hline & & & Other: current pediatric guidelines do not recommend use \\
\hline \multicolumn{4}{|l|}{ Intravenous } \\
\hline Enalaprilat & ACE inhibitor & $\begin{array}{l}\text { Bolus dosing: } 0.05-0.1 \mathrm{mg} / \mathrm{kg} \\
\text { per dose, up to } 1.25 \mathrm{mg} \\
\text { per dose }\end{array}$ & $\begin{array}{l}\text { Onset of action: } \leq 15 \text { minutes } \\
\text { Adverse effects: acute kidney injury, hyperkalemia, hypotension } \\
\text { Other: neonates are at increased risk for prolonged hypotension and acute } \\
\text { kidney injury }\end{array}$ \\
\hline Esmolol & $\beta$-Blocker & $\begin{array}{l}\text { Continuous infusion: loading } \\
\text { dose } 100-500 \mu g / k g \\
\text { then } 50-300 \mu g / k g / m i n \\
\text { (continuous infusion) }\end{array}$ & $\begin{array}{l}\text { Onset of action: }<I \text { minute } \\
\text { Adverse effects: bradycardia, decreased cardiac output, bronchospasm } \\
\text { Other: use with caution in patients with heart failure due to negative inotropic } \\
\text { effects }\end{array}$ \\
\hline Fenoldopam & $\begin{array}{l}\text { Dopamine } \\
\text { (D,-receptor) } \\
\text { agonist }\end{array}$ & $\begin{array}{l}\text { Continuous infusion: } \\
0.2-0.8 \mu \mathrm{g} / \mathrm{kg} / \mathrm{min}\end{array}$ & $\begin{array}{l}\text { Onset of action: } 10 \text { minutes } \\
\text { Adverse effects: tachycardia, headache, nausea, flushing, hypotension, } \\
\text { hypokalemia } \\
\text { Other: putative benefit of increasing renal perfusion }\end{array}$ \\
\hline Hydralazine & Vasodilator & 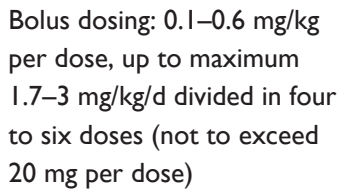 & $\begin{array}{l}\text { Onset of action: } 5-20 \text { minutes } \\
\text { Adverse effects: hypotension, reflex tachycardia, flushing, headaches, lupus-like } \\
\text { syndrome } \\
\text { Other: use with caution due to risk of precipitous drop in BP; paradoxical rise } \\
\text { in BP may be observed in setting of renin-mediated hypertension }\end{array}$ \\
\hline Labetalol & $\begin{array}{l}\text { Alpha- and } \\
\text { beta-blocker }\end{array}$ & $\begin{array}{l}\text { Bolus dosing: } 0.2-1 \mathrm{mg} / \mathrm{kg} \\
\text { per dose, up to a maximum } \\
\text { of } 40 \mathrm{mg} \text { per dose; } \\
\text { continuous infusion: } \\
0.2-3 \mathrm{mg} / \mathrm{kg} / \mathrm{h}\end{array}$ & $\begin{array}{l}\text { Onset of action: } 2-5 \text { minutes } \\
\text { Adverse effects: hypotension, dizziness, nausea, bradycardia, bronchospasm } \\
\text { Other: use should be avoided in those with heart failure or reactive airway } \\
\text { disease }\end{array}$ \\
\hline \multirow[t]{4}{*}{ Nicardipine } & $\mathrm{CCB}$ & Continuous infusion: & Onset of action: within minutes \\
\hline & & $0.5-3 \mu g / \mathrm{kg} / \mathrm{min}$ & Adverse effects: reflex tachycardia, peripheral edema \\
\hline & & & $\begin{array}{l}\text { Other: use with caution in those with heart failure due to negative inotropic } \\
\text { effect }\end{array}$ \\
\hline & & & Central access is preferred for infusion due to risk of injection site reaction \\
\hline Sodium & Vasodilator & Continuous infusion: & Onset of action: $<2$ minutes \\
\hline \multirow[t]{3}{*}{ nitroprusside } & & $0.5-10 \mu g / k g / m i n$ & Adverse effects: hypotension, palpitations, flushing \\
\hline & & & Other: monitor for cyanide toxicity with prolonged use or when administered \\
\hline & & & in those with concomitant renal or liver failure \\
\hline
\end{tabular}

Abbreviations: ACE, angiotensin converting enzyme; BP, blood pressure; CCB, calcium channel blocker; d, day; EKG, electrocardiogram; h, hour. 
however, in cases with less severe BP elevation or difficulty in obtaining IV access, oral medications are often used. Historically, oral hydralazine and immediate-acting nifedipine were the agents used most frequently. Minoxidil and clonidine have also been used for this purpose. More recently, isradipine has emerged as the oral agent of choice for use in children with severely elevated BP.

\section{Oral medications}

Nifedipine is a dihydropyridine calcium channel blocker (CCB) that produces a reduction in BP primarily through peripheral vasodilation, although a negative inotropic effect plays a role as well. There is a limited body of published literature regarding the use of immediate-acting nifedipine in the pediatric population, although older studies do suggest some utility in the treatment of hypertensive crisis. ${ }^{14-17}$ More recently, however, the use of nifedipine in this setting has been avoided as it has been associated with precipitous drops in BP and an increased risk for myocardial infarction, stroke, and death in the adult population. ${ }^{18}$ In children, nifedipine has also been shown to produce a robust drop in BP. In a retrospective review of 520 nifedipine doses in 117 patients, Blaszak et al ${ }^{19}$ reported that $35 \%$ were associated with $\geq 25 \%$ reduction in mean arterial pressure (MAP). In addition, Egger et $\mathrm{al}^{20}$ reviewed 1,746 doses of oral nifedipine in 166 pediatric patients and reported mean reductions in systolic and diastolic BP of $28 \%$ and $43 \%$, respectively, within 6 hours of medication administration. Although the complication rate in both studies was low, it is notable that the reported decrease in BP frequently exceeded the recommended rate of gradual $\mathrm{BP}$ reduction in children with hypertensive crisis discussed previously. Furthermore, use of immediate-acting nifedipine in young children requires the contents of the capsule to be drawn into a syringe and a measured dose to be administered orally, a process that is likely to increase the likelihood of dosing error. Given the availability of safer alternatives, many experts have advocated abandoning the use of immediateacting nifedipine in children with hypertensive crisis. ${ }^{21,22}$

Hydralazine and minoxidil lower the BP by relaxing the arteriolar smooth muscle, with a resultant decrease in peripheral vascular resistance. Although FDA-approved pediatric labeling exists to guide hydralazine dosing, there are notably few safety or efficacy data guiding its use in childhood. In our own experience, there is little role for oral hydralazine in the management of pediatric hypertensive crises as it is less effective and poorly studied, though bolus IV dosing (discussed later in the "IV medications" section) remains an option and its use continues to be widespread. Several single-center case series have been published describing the use of minoxidil in children, suggesting efficacy in the treatment of severe childhood hypertension, particular in those children with acute BP elevation in the setting of chronic hypertension and those with hypertension refractory to other medications. ${ }^{23-26}$

Clonidine inhibits central sympathetic outflow, resulting in decreased peripheral vascular resistance. Published reports regarding use in pediatrics are sparse and limited to oral or transdermal administration in adolescents with chronic hypertension. ${ }^{27,28}$ Others have reported good results with clonidine administration in the hemodialysis patient with acute BP elevation due to the fact that it is minimally dialyzed and requires no dose adjustment in the setting of renal failure. ${ }^{3}$ We have also found clonidine particularly useful in the intensive care setting to control catecholamineinduced symptoms, including hypertension, associated with withdrawal of sedation as well as in those with neurologically medicated hypertension and recent traumatic brain injury.

Isradipine is a second-generation dihydropyridine CCB, which, similar to nifedipine, reduces BP primarily through a decrease in systemic vascular resistance. A number of single-center case series have been published evaluating isradipine use in hospitalized children with acutely elevated $\mathrm{BP}^{29-32}$ In these studies, isradipine consistently was shown to be effective in reducing systolic and diastolic BP with a low rate of adverse events. A stable extemporaneous solution can be compounded, facilitating reliable dosing in infants and young children. On the basis of these factors, isradipine has emerged as the oral antihypertensive medication of choice for use in pediatric hypertensive crises by some providers, ${ }^{3}$ including the authors of this review.

\section{IV medications}

Hypertensive crises in children are most often treated using IV antihypertensive medications. Some of these agents may be administered by intermittent bolus dosing and others by continuous infusion. In general, it is our preference to use the latter in cases of hypertensive emergencies due to the ability to titrate the dose quickly and reduce the BP in a controlled, gradual manner. Bolus dosing, however, may be appropriate in cases of less severe BP elevation and in the absence of overt end-organ damage.

Historically, IV hydralazine has almost certainly been used more than any other agent in the treatment of children with acutely elevated BP, though there are few data to back this assertion. There is also paucity of data with respect to efficacy and safety of its use in the pediatric population. That being said, results from two recent single-center retrospective 
studies evaluating the efficacy and safety of IV hydralazine in hospitalized children are now available. In 110 hospitalized children, Ostrye et $\mathrm{al}^{33}$ reported a median reduction in systolic and diastolic BP of $8.5 \%$ and $11.5 \%$, respectively. Of some concern, $21 \%$ of patients studied achieved a BP reduction exceeding 25\% and an increase in BP was observed in $30 \%$ of the patients. A low rate of adverse effects $(9 \%)$ was observed..$^{33}$ Recent data were additionally published in abstract form by Flynn et al, ${ }^{34}$ who analyzed 141 first doses of hydralazine in hospitalized children. An average reduction in MAP of 19\% was observed and a clinical response, defined as $10 \%-25 \%$ reduction in MAP, was demonstrated in $47 \%$ of patients. Similar to the aforementioned results by Ostrye et al, ${ }^{33}$ a substantial number of patients $(31 \%)$ demonstrated a potentially excessive BP drop, defined as $>25 \%$ MAP reduction. ${ }^{34}$

Labetalol is a combined $\alpha_{1}$ - and $\beta$-adrenergic blocking agent that is available in oral and IV formulations. The ratio of $\alpha$ - to $\beta$-blockade differs depending on the route of administration, with a relative potency of $1: 3$ or $1: 7$, respectively, when given through the oral or IV route. In the setting of hypertensive crises, IV delivery is preferred due to the rapid onset of action (2-5 minutes). When administered by the IV route, labetalol may be given via intermittent bolus dosing or via continuous infusion, the latter of which is generally used in the setting of more severe BP elevation. There are limited studies evaluating the use of labetalol in hypertensive children, although single-center case series suggest effective BP reduction. ${ }^{12,35,36}$ Thomas et $\mathrm{al}^{36}$ reported a risk for the development of hypotension when used in infants and young children ( $\leq 24$ months) with hypertensive crisis and concomitant ischemic or traumatic brain injury.

Nicardipine is the first dihydropyridine CCB compatible with IV delivery and may be administered by bolus dosing, although continuous infusion is more typically used in children. A number of single-center case series evaluating the use of nicardipine in children with severely elevated $\mathrm{BP}$ in a variety of disease states and age groups, including hypertensive premature infants, have been published. ${ }^{37-43}$ All of these reports found nicardipine to be effective in reducing BP with a low rate of adverse effects, although cases of thrombophlebitis were reported across several of the studies. In this setting, it is recommended that nicardipine be administered through a central line. If delivered through a peripheral vein, irritation may be minimized by changing the site of infusion every 12 hours.

Esmolol is an ultra-short-acting cardioselective $\beta_{1}$-adrenoreceptor antagonist that is typically administered as a bolus dose followed by continuous infusion. Unlike other medications described thus far, the pharmacodynamics and pharmacokinetics of esmolol have been well characterized in children and found to be similar to those in older patients, although drug elimination has been shown to be more rapid in younger age groups. ${ }^{44-46}$ In case reports and small series, esmolol has been found to be safe and effective in hypertensive children, particularly in those with elevated $\mathrm{BP}$ in the postoperative period following cardiac surgery. ${ }^{47-49}$ In addition, a more recent multicenter double-blind randomized trial showed that esmolol was safe and effective in reducing BP at low $(125 \mu \mathrm{g} / \mathrm{kg})$, medium $(250 \mu \mathrm{g} / \mathrm{kg})$, and high $(500 \mu \mathrm{g} / \mathrm{kg})$ doses in infants and young children following repaired coarctation of the aorta, although no dose response was demonstrated. ${ }^{46}$

Sodium nitroprusside is a short-acting direct vasodilator that is administered by continuous infusion. It is rapidly metabolized to nitric oxide, which results in preload and afterload reduction via dilation of arteriolar and venous smooth muscle cells. Although there is long-standing experience utilizing sodium nitroprusside in children with hypertensive crisis, studies evaluating efficacy and safety are notably lacking. Older case studies and series suggest rapid response with improved BP and a low incidence of complications. ${ }^{50,51}$ Extended use and use with concomitant renal or liver dysfunction is generally avoided due to the risk for toxic metabolite accumulation, particularly cyanide and thiocyanate. Encouragingly, recent studies have evaluated nitroprusside use in children in a more rigorous manner. In a randomized, double-blind withdrawal to placebo study, Hammer et $\mathrm{al}^{52}$ demonstrated that sodium nitroprusside was efficacious in controlling BP in a majority of subjects and was superior to placebo following a 12-hour infusion. Of concern, a significant number of subjects exhibited elevated cyanide levels, although none showed overt evidence of toxicity.

Fenoldopam is a selective postsynaptic dopamine $\mathrm{D}_{1}$-like receptor agonist that reduces BP by decreasing peripheral vasculature resistance and increasing renal blood flow and natriuresis. It is administered by continuous IV infusion. Adult studies have found fenoldopam to have efficacy comparable to that of sodium nitroprusside in reducing BP in the setting of hypertensive crisis. ${ }^{53,54}$ Studies evaluating the use of fenoldopam in hypertensive children are lacking. Hammer et $\mathrm{al}^{55}$ conducted a randomized, multicenter, placebo-controlled dose-ranging study in 77 pediatric patients requiring deliberate intraoperative hypotension. They found fenoldopam to be safe and effective in reducing BP in this population with similar pharmokinetic and side effect profiles 
as those reported in adults; however, the effective dose range was significantly higher in children than in adults.

Enalaprilat is the only FDA-approved angiotensinconverting enzyme (ACE) inhibitor available in IV form. Enalaprilat is delivered by intermittent IV dosing and produces its antihypertensive effect primarily through vasodilation and decreased peripheral vascular resistance. The safety and efficacy of enalaprilat for BP control in children have not been rigorously studied, although case studies and series have been published to suggest good antihypertensive effect in a variety of ages, ranging from infancy to adulthood. ${ }^{56-59}$ Given evidence of more profound BP reduction in those with renin-mediated hypertension, particular caution is advised in pediatric patients who have a higher risk of renal vascular hypertension and renal parenchymal disease. Additionally, those with bilateral renal artery stenosis are at risk for acute renal injury if ACE inhibitors are used, and thus this class of medications may be contraindicated in such cases. In the case of unilateral renal artery stenosis, ACE inhibitor therapy may result in a profound reduction in $\mathrm{BP}$ and thus close monitoring and small dose adjustments are required.

Clevidipine is a newer calcium channel antagonist that acts selectively on arteriolar resistance vessels, with little effect on the venous capacitance bed. Similar to nicardipine, it is administered by continuous IV infusion, though with a much shorter duration of action as it is rapidly hydrolyzed to inactive metabolites by blood and tissue esterases. ${ }^{60,61}$ Clevidipine has been well studied in the adult population, particularly in those requiring BP reduction during surgical procedures. Recent case studies and series suggest that clevidipine is also effective in controlling perioperative BP in children with a number of conditions, including renal failure, pheochromocytoma, and congenital heart disease. ${ }^{62-65}$ In addition, a recently completed trial found that clevidipine is safe and effective in children requiring controlled hypotension during posterior spinal fusion surgery. ${ }^{66}$ Given this early experience, there is optimism that clevidipine may prove useful in the treatment of children with hypertensive crisis, although further study is required to establish efficacy, safety, and dosing recommendations in this setting.

\section{Approach to management}

The initial goal in the management of the child who presents with hypertensive crisis is stabilization and the gradual reduction of BP in a controlled manner. In our experience, this is best accomplished in the intensive care unit setting using a continuous infusion of one of the aforementioned IV antihypertensive agents, although oral agents may be considered
Table 7 Targeted approach to antihypertensive drug therapy

\begin{tabular}{ll}
\hline Condition & Medication \\
\hline Renovascular disease (unilateral) & $\begin{array}{l}\text { ACE-inhibitor, ARB, diuretic, } \\
\text { vasodilator }\end{array}$ \\
$\begin{array}{l}\text { Chronic kidney disease } \\
\text { Acute nephritis }\end{array}$ & $\begin{array}{l}\text { ACE-inhibitor, ARB } \\
\text { Loop diuretic, vasodilator }\end{array}$ \\
Obesity-related hypertension & Beta-blocker \\
Pheochromocytoma & ACE-inhibitor, ARB \\
Monogenic forms of hypertension & Alpha- and beta-blockers \\
Liddle syndrome & \\
Apparent mineralocorticoid excess & Amiloride, triamterene \\
Glucocorticoid remedial & Spironolactone, eplerenone \\
aldosteronism & Amiloride, triamterene, \\
Gordon syndrome & glucocorticoids \\
\hline
\end{tabular}

Abbreviations: $A C E$, angiotensin-converting enzyme; $A R B$, angiotensin receptor blocker.

in less severe cases. Selection of an initial medication is often based on provider preference rather than a physiologic advantage of the medication in question. In our opinion, labetalol or nicardipine both represent reasonable first-line therapies, although esmolol or sodium nitroprusside may be considered in special circumstances such as acute intraoperative BP elevation. Once initiated, the infusion should be carefully titrated to the desired effect.

Once the BP has been reduced to an acceptable level, transition to an appropriate oral medication for chronic BP control should be initiated. When selecting an agent, one should aim to maximize the antihypertensive potential while simultaneously minimizing the likelihood of side effects. If possible, utilizing a medication that targets the pathophysiologic process that mediates the BP elevation or that has putative benefits in the setting of comorbid conditions is preferred. A detailed discussion related to the rational selection of antihypertensive medications in children has been provided elsewhere; however, preferred agents in specific clinical situations are provided in Table $7 .{ }^{67}$

\section{Conclusion}

Hypertensive crises are medical emergencies that require thorough evaluation and prompt meticulous management. IV antihypertensive medications are typically used in the acute setting to allow for judicious titration and gradual BP reduction. Following stabilization, transition to oral therapy for long-term BP control is undertaken. Identification of an underlying cause for the BP elevation may guide therapeutic choices.

\section{Disclosure}

The authors report no conflicts of interest in this work. 


\section{References}

1. National High Blood Pressure Education Program Working Group on High Blood Pressure in Children and Adolescents. The fourth report on the diagnosis, evaluation, and treatment of high blood pressure in children and adolescents. Pediatrics. 2004;114(2 suppl 4th Report):555-576.

2. Chobanian AV, Bakris GL, Black HR, et al. The Seventh Report of the Joint National Committee on Prevention, Detection, Evaluation, and Treatment of High Blood Pressure: the JNC 7 report. JAMA. 2003;289(19):2560-2572.

3. Flynn JT, Tullus K. Severe hypertension in children and adolescents: pathophysiology and treatment. Pediatr Nephrol. 2009;24(6): 1101-1112.

4. Yang WC, Zhao LL, Chen CY, Wu YK, Chang YJ, Wu HP. First-attack pediatric hypertensive crisis presenting to the pediatric emergency department. BMC Pediatr. 2012;12:200.

5. Beacher DR, Chang SZ, Rosen JS, et al. Recognition of elevated blood pressure in an outpatient pediatric tertiary care setting. $J$ Pediatr. 2015;166(5):1233e-1239e.

6. Brady TM, Solomon BS, Neu AM, Siberry GK, Parekh RS. Patient-, provider-, and clinic-level predictors of unrecognized elevated blood pressure in children. Pediatrics. 2010;125(6):e1286-e1293.

7. Hansen ML, Gunn PW, Kaelber DC. Underdiagnosis of hypertension in children and adolescents. JAMA. 2007;298(8):874-879.

8. Freedman DS, Dietz WH, Srinivasan SR, Berenson GS. The relation of overweight to cardiovascular risk factors among children and adolescents: the Bogalusa Heart Study. Pediatrics. 1999;103(6 pt 1): 1175-1182.

9. Ostchega Y, Carroll M, Prineas RJ, McDowell MA, Louis T, Tilert T. Trends of elevated blood pressure among children and adolescents: data from the National Health and Nutrition Examination Survey 1988-2006. Am J Hypertens. 2009;22(1):59-67.

10. Baracco R, Mattoo TK. Pediatric hypertensive emergencies. Cur Hypertens Rep. 2014;16(8):456.

11. Chandar J, Zilleruelo G. Hypertensive crisis in children. Pediatr Nephrol. 2012;27(5):741-751.

12. Deal JE, Barratt TM, Dillon MJ. Management of hypertensive emergencies. Arch Dis Child. 1992;67(9):1089-1092.

13. Yang WC, Wu HP. Clinical analysis of hypertension in children admitted to the emergency department. Pediatr Neonatol. 2010;51(1):44-51.

14. Dilmen U, Caglar MK, Senses DA, et al. Nifedipine in hypertensive emergencies of children. Am J Dis Child. 1983;137(12):1162-1165.

15. Evans JH, Shaw NJ, Brocklebank JT. Sublingual nifedipine in acute severe hypertension. Arch Dis Child. 1988;63(8):975-977.

16. Roth B, Herkenrath P, Krebber J, et al. Nifedipine in hypertensive crises of infants and children. Clin Exp Hypertens A. 1986;8(4-5):871-877.

17. Siegler RL, Brewer ED. Effect of sublingual or oral nifedipine in the treatment of hypertension. Journal Pediatr. 1988;112(5):811-813.

18. Grossman E, Messerli FH, Grodzicki T, et al. Should a moratorium be placed on sublingual nifedipine capsules given for hypertensive emergencies and pseudoemergencies? JAMA. 1996;276(16):1328-1331.

19. Blaszak RT, Savage JA, Ellis EN. The use of short-acting nifedipine in pediatric patients with hypertension. Journal Pediatr. 2001; 139(1):34-37.

20. Egger DW, Deming DD, Hamada N, et al. Evaluation of the safety of short-acting nifedipine in children with hypertension. Pediatr Nephrol. 2002;17(1):35-40.

21. Flynn JT. Safety of short-acting nifedipine in children with severe hypertension. Expert Opin Drug Saf. 2003;2(2):133-139.

22. Truttmann AC, Zehnder-Schlapbach S, Bianchetti MG. A moratorium should be placed on the use of short-acting nifedipine for hypertensive crises. Pediatric Nephrol. 1998;12(3):259.

23. Pennisi AJ, Takahashi M, Bernstein BH, et al. Minoxidil therapy in children with severe hypertension. Journal Pediatr. 1977;90(5):813-819.

24. Puri HC, Maltz HE, Kaiser BA, Potter DE. Severe hypertension in children with renal disease: treatment with minoxidil. Am J Kidney Dis. 1983;3(1):71-75.
25. Sinaiko AR, Mirkin BL. Management of severe childhood hypertension with minoxidil: a controlled clinical study. J Pediatr. 1977;91(1):138-142.

26. Strife CF, Quinlan M, Waldo FB, et al. Minoxidil for control of acute blood pressure elevation in chronically hypertensive children. Pediatrics. 1986;78(5):861-865.

27. Falkner B, Onesti G, Lowenthal DT, Affrime MB. The use of clonidine monotherapy in adolescent hypertension. Chest. 1983;83(2 suppl): 425-427.

28. Falkner B, Thanki B, Lowenthal DT. Transdermal clonidine in the treatment of adolescent hypertension. J Hyper Suppl. 1985;3(4):S61-S63.

29. Flynn JT, Warnick SJ. Isradipine treatment of hypertension in children: a single-center experience. Pediatr Nephrol. 2002;17(9):748-753.

30. Johnson CE, Jacobson PA, Song MH. Isradipine therapy in hypertensive pediatric patients. Ann Pharmacother. 1997;31(6):704-707.

31. Miyashita Y, Peterson D, Rees JM, Flynn JT. Isradipine for treatment of acute hypertension in hospitalized children and adolescents. J Clin Hypertens (Greenwich). 2010;12(11):850-855.

32. Strauser LM, Groshong T, Tobias JD. Initial experience with isradipine for the treatment of hypertension in children. South Med J. 2000;93(3):287-293.

33. Ostrye J, Hailpern SM, Jones J, Egan B, Chessman K, Shatat IF. The efficacy and safety of intravenous hydralazine for the treatment of hypertension in the hospitalized child. Pediatr Nephrol. 2014;29(8):1403-1409.

34. Flynn J, Bradford M, Harvey E. Intravenous hydralazine in hypertensive pediatric inpatients: does it work? is it safe? J Am Soc of Hypertens. 2014;8(4S):e130.

35. Bunchman TE, Lynch RE, Wood EG. Intravenously administered labetalol for treatment of hypertension in children. J Pediatr. 1992;120(1):140-144.

36. Thomas CA, Moffett BS, Wagner JL, Mott AR, Feig DI. Safety and efficacy of intravenous labetalol for hypertensive crisis in infants and small children. Pediatr Crit Care Med. 2011;12(1):28-32.

37. Flynn JT, Mottes TA, Brophy PD, Kershaw DB, Smoyer WE, Bunchman TE. Intravenous nicardipine for treatment of severe hypertension in children. J Pediatr. 2001;139(1):38-43.

38. Gouyon JB, Geneste B, Semama DS, Françoise M, Germain JF. Intravenous nicardipine in hypertensive preterm infants. Arch Dis Child Fetal Neonatal Ed. 1997;76(2):F126-F127.

39. Michael J, Groshong T, Tobias JD. Nicardipine for hypertensive emergencies in children with renal disease. Pediatr Nephrol. 1998;12(1):40-42.

40. Nakagawa TA, Sartori SC, Morris A, Schneider DS. Intravenous nicardipine for treatment of postcoarctectomy hypertension in children. Pediatr Cardiol. 2004;25(1):26-30.

41. Tenney F, Sakarcan A. Nicardipine is a safe and effective agent in pediatric hypertensive emergencies. Am J Kidney Dis. 2000;35(5):E20.

42. Tobias JD. Nicardipine to control mean arterial pressure after cardiothoracic surgery in infants and children. Am J Ther. 2001;8(1): 3-6.

43. Treluyer JM, Hubert P, Jouvet P, Couderc S, Cloup M. Intravenous nicardipine in hypertensive children. Eur J Pediatr. 1993;152(9): $712-714$.

44. Adamson PC, Rhodes LA, Saul JP, et al. The pharmacokinetics of esmolol in pediatric subjects with supraventricular arrhythmias. Pediatr Cardiol. 2006;27(4):420-427.

45. Cuneo BF, Zales VR, Blahunka PC, Benson DW Jr. Pharmacodynamics and pharmacokinetics of esmolol, a short-acting beta-blocking agent, in children. Pediatr Cardiol. 1994;15(6):296-301.

46. Tabbutt S, Nicolson SC, Adamson PC, et al. The safety, efficacy, and pharmacokinetics of esmolol for blood pressure control immediately after repair of coarctation of the aorta in infants and children: a multicenter, double-blind, randomized trial. J Thorac Cardiovasc Surg. 2008;136(2):321-328.

47. Smerling A, Gersony WM. Esmolol for severe hypertension following repair of aortic coarctation. Crit Care Med. 1990;18(11):1288-1290. 
48. Vincent RN, Click LA, Williams HM, Plauth WH, Williams WH. Esmolol as an adjunct in the treatment of systemic hypertension after operative repair of coarctation of the aorta. Am J Cardiol. 1990;65(13):941-943.

49. Wiest DB, Garner SS, Uber WE, Sade RM. Esmolol for the management of pediatric hypertension after cardiac operations. J Thorac Cardiovas Surg. 1998;115(4):890-897.

50. Gordillo-Paniagua G, Velasquez-Jones L, Martini R, Valdez-Bolaños E. Sodium nitroprusside treatment of severe arterial hypertension in children. J Pediatr. 1975;87(5):799-802.

51. Luderer JR, Hayes AH Jr, Dubnsky O, Berlin CM. Long-term administration of sodium nitroprusside in childhood. J Pediatr. 1977;91(3):490-491.

52. Hammer GB, Lewandowski A, Drover DR, et al. Safety and efficacy of sodium nitroprusside during prolonged infusion in pediatric patients. Pediatr Crit Care Med. 2015;16(5):397-403.

53. Devlin JW, Seta ML, Kanji S, Somerville AL. Fenoldopam versus nitroprusside for the treatment of hypertensive emergency. Annals Pharmacother. 2004;38(5):755-759.

54. Panacek EA, Bednarczyk EM, Dunbar LM, Foulke GE, Holcslaw TL. Randomized, prospective trial of fenoldopam vs sodium nitroprusside in the treatment of acute severe hypertension. Fenoldopam Study Group. Acad Emerg Med. 1995;2(11):959-965.

55. Hammer GB, Verghese ST, Drover DR, Yaster M, Tobin JR. Pharmacokinetics and pharmacodynamics of fenoldopam mesylate for blood pressure control in pediatric patients. BMC Anesthesiol. 2008;8:6.

56. Rheuban KS, Carpenter MA, Ayers CA, Gutgesell HP. Acute hemodynamic effects of converting enzyme inhibition in infants with congestive heart failure. J Pediatr. 1990;117(4):668-670.

57. Rouine-Rapp K, Mello DM, Hanley FL, Mohan Reddy V, Soifer S. Effect of enalaprilat on postoperative hypertension after surgical repair of coarctation of the aorta. Pediatr Crit Care Med. 2003;4(3):327-332.
58. Wells TG, Bunchman TE, Kearns GL. Treatment of neonatal hypertension with enalaprilat. J Pediatr. 1990;117(4):664-667.

59. Zawaideh MA, Duncan B, Joseph MW, Dixit MP. Treatment of chronic hypertension with intravenous enalaprilat and transdermal clonidine. Pediatr Nephrol. 2001;16(1):85-86.

60. Ericsson H, Fakt C, Hoglund L, et al. Pharmacokinetics and pharmacodynamics of clevidipine in healthy volunteers after intravenous infusion. Eur J Clin Pharmacol. 1999;55(1):61-67.

61. Nordlander M, Sjoquist PO, Ericsson H, Rydén L. Pharmacodynamic, pharmacokinetic and clinical effects of clevidipine, an ultrashort-acting calcium antagonist for rapid blood pressure control. Cardiovasc Drug Rev. 2004;22(3):227-250

62. Bettesworth JG, Martin DP, Tobias JD. Intraoperative use of clevidipine in a patient with von Hippel-Lindau disease with associated pheochromocytoma. J Cardiothorac Vasc Anesth. 2013;27(4):749-751.

63. Tobias JD, Allee J, Ramachandran V, et al. Clevidipine controls intraoperative blood pressure in an adolescent with renal failure. $J$ Pediatr Pharmacol Ther. 2009;14(3):144-147.

64. Tobias JD, Schechter WS, Phillips A, et al. Clevidipine for perioperative blood pressure control in infants and children undergoing cardiac surgery for congenital heart disease. $J$ Pediatr Pharmacol Ther. 2011;16(1):55-60.

65. Towe E, Tobias JD. Preliminary experience with clevidipine in the pediatric population. J Intensive Care Med. 2010;25(6):349-352.

66. Kako H, Gable A, Martin D, et al. A prospective, open-label trial of clevidipine for controlled hypotension during posterior spinal fusion. J Pediatr Pharmacol Ther. 2015;20(1):54-60.

67. Ferguson MA, Flynn JT. Rational use of antihypertensive medications in children. Pediatr Nephrol. 2014;29(6):979-988.
Integrated Blood Pressure Control

\section{Publish your work in this journal}

Integrated Blood Pressure Control is an international, peer-reviewed open-access journal focusing on the integrated approach to managing hypertension and risk reduction. Treating the patient and comorbidities together with diet and lifestyle modification and optimizing healthcare resources through a multidisciplinary team approach constitute key

\section{Dovepress}

features of the journal. This journal is indexed on American Chemical Society's Chemical Abstracts Service (CAS). The manuscript management system is completely online and includes a very quick and fair peerreview system, which is all easy to use. Visit http://www.dovepress.com/ testimonials.php to read real quotes from published authors 